Paper ID \#19163

\title{
Practicing What we Preach: A Multi-Disciplinary Team Teaching Multi-Disciplinary Teamwork
}

\section{Dr. Ada Hurst, University of Waterloo}

Ada Hurst is a Lecturer in the Department of Management Sciences at the University of Waterloo. She has taught and coordinated the capstone design project course for the Management Engineering program since 2011. She also teaches courses in organizational behavior, theory, and technology. She received a Bachelor of Applied Science in Electrical Engineering, followed by Master of Applied Science and Doctor of Philosophy degrees in Management Sciences, all from the University of Waterloo. Ada's research and teaching interests include decision making under uncertainty, subjective probability, gender issues in STEM disciplines, design teaching, experiential and online learning, team processes, and peer review.

\section{Mehrnaz Mostafapour, University of Waterloo \\ Dr. Rania Al-Hammoud P.Eng., University of Waterloo}

Dr. Al-Hammoud is a Faculty lecturer (Graduate Attributes) in the department of civil and environmental engineering at the University of Waterloo. Dr. Al-Hammoud has a passion for teaching where she continuously seeks new technologies to involve students in their learning process. She is actively involved in the Ideas Clinic, a major experiential learning initiative at the University of Waterloo. She is also responsible for developing a process and assessing graduate attributes at the department to target areas for improvement in the curriculum. This resulted in several publications in this educational research areas. Dr. Al-Hammoud won a couple of teaching awards in 2014 and 2016 from University of Waterloo. Her students regard her as an innovative teacher who introduced new ideas to the classroom. Such ideas include using "props" to increase students' understanding of the materials, as well as using new technology such as i-clickers and IF-AT cards. Dr. Al-Hammoud also organized a bridge-building contest in one of her courses where she worked with other professors in the department to integrate the project horizontally across the curriculum.

\section{Dr. Andrea Prier, University of Waterloo}

Andrea Prier is the Senior Academic Development Specialist within the Student Success Office at the University of Waterloo. She holds a PhD from the University of Windsor in the field of Cognition and Learning. Andrea's research interests include STEM education and the design of research informed retention initiatives.

\section{Ms. Erin Jobidon, University of Waterloo}

Academic Development Specialist

\section{Dr. Carol Hulls, University of Waterloo}

Dr. Carol Hulls, P.Eng. is a Continuing Lecturer in the Mechanical and Mechatronics Engineering Department at the University of Waterloo. She has been teaching courses in programming, robotics, and digital logic since 1999. Always looking to improve classroom learning, she has tried a variety of techniques including Tablet teaching, flipped classrooms, and experiential learning. She received her BASc, MASc, and PhD from the University of Waterloo in Electrical and Computer Engineering. In 2016 she was awarded the STLHE-Brightspace Innovation Award in Teaching and Learning.

\section{Mr. Christopher Rennick, University of Waterloo}

Mr. Christopher Rennick received his B.A.Sc., Electrical Engineering in 2007 and his M.A.Sc. in Electrical Engineering in 2009, both from the University of Windsor, in Windsor, Ontario, Canada. Since 2010, he has been employed with the University of Waterloo, as teaching staff in First Year Engineering.

\section{Dr. Jason Grove P.E., University of Waterloo}


Jason Grove is the Graduate Attributes Lecturer in the Department of Chemical Engineering at the University of Waterloo. He is responsible for leading the continuous program assessment improvement process for the chemical and nanotechnology engineering programs. He is also heavily involved in the development of Waterloo Engineering's IDEAS Clinic initiative.

Dr. Grove obtained his PhD from the University of Waterloo investigating the microbial community ecology in biofilters used for air pollution control. He obtained his undergraduate degree in Engineering Science from the University of Oxford.

\section{Eugene Li, University of Waterloo \\ Prof. Sanjeev Bedi P.Eng., University of Waterloo}

Dr. Sanjeev Bedi is the Director of the Engineering Ideas Clinic. He earned his PhD from the University of Victoria in 1987. As a Professor of Mechanical Engineering at the University of Waterloo, his research focus is machining, and he is well known for developing innovative 5-axis tool-positioning and flankmilling techniques. 


\title{
Practicing What We Preach: A Multi-Disciplinary Team Teaching Multi-Disciplinary Teamwork
}

\begin{abstract}
The Faculty of Engineering at the University of Waterloo has recognized that the development of student teamwork skills requires immediate attention across all undergraduate programs. A multi-disciplinary team was assembled to address this challenge via the design and implementation of a set of learning modules. The team was made up of engineering faculty members, graduate students, and representatives from a student support unit, a teaching support unit, and the First Year Engineering office. In itself, a study of the dynamics and achievements of this team of faculty and staff members from across campus provides a rich opportunity to examine authentic team behaviour. It can also serve as a model for others considering the launch of educational initiatives involving people from a wide variety of departments and units.

In this paper, we describe what we have learned about assembling, and working effectively in, a multi-disciplinary team. Placing it all in the context of the literature on teams and team performance, we discuss the initiative and team formation; conflicts that occurred while developing the modules and how they were handled by the team; and the immense value and challenges that exist in working within a multi-disciplinary team. We also describe some of the obstacles that emerge when integrating teamwork training in engineering curricula while operating largely outside formal curriculum committees.
\end{abstract}

\section{Introduction}

Recognizing that the ability to work effectively in teams is of great importance to engineering professionals, many universities have undertaken initiatives to improve engineering students' teamwork skills. While some of these initiatives have emphasized increased opportunities for students to work in intensive team settings - believing that the experience will organically lead to improved teamwork skills - others have taken more explicit teaching approaches in the form of modular instructional units that are more easily integrated by faculty in various academic disciplines and at various course levels (Shuman, Besterfield-Sacre, \& McGourty, 2005).

We have undertaken a similar initiative at the University of Waterloo, using the latter approach. Believing that immersive team experiences alone are not sufficient in developing student teamwork skills, a team of faculty, staff, and graduate students representing various engineering departments and other teaching and student support units is developing a series of six teamwork modules offered to undergraduate engineering students in each academic term from first- to third-year. The series comprises three introductory modules, two reinforcement modules, and one mastery module - all to be completed before the students' capstone design project in their 
final year (see Figure 1). Each module is designed around an experiential activity that necessitates the application of teamwork skills within a relevant context, as dictated by the engineering course that hosts the activity.

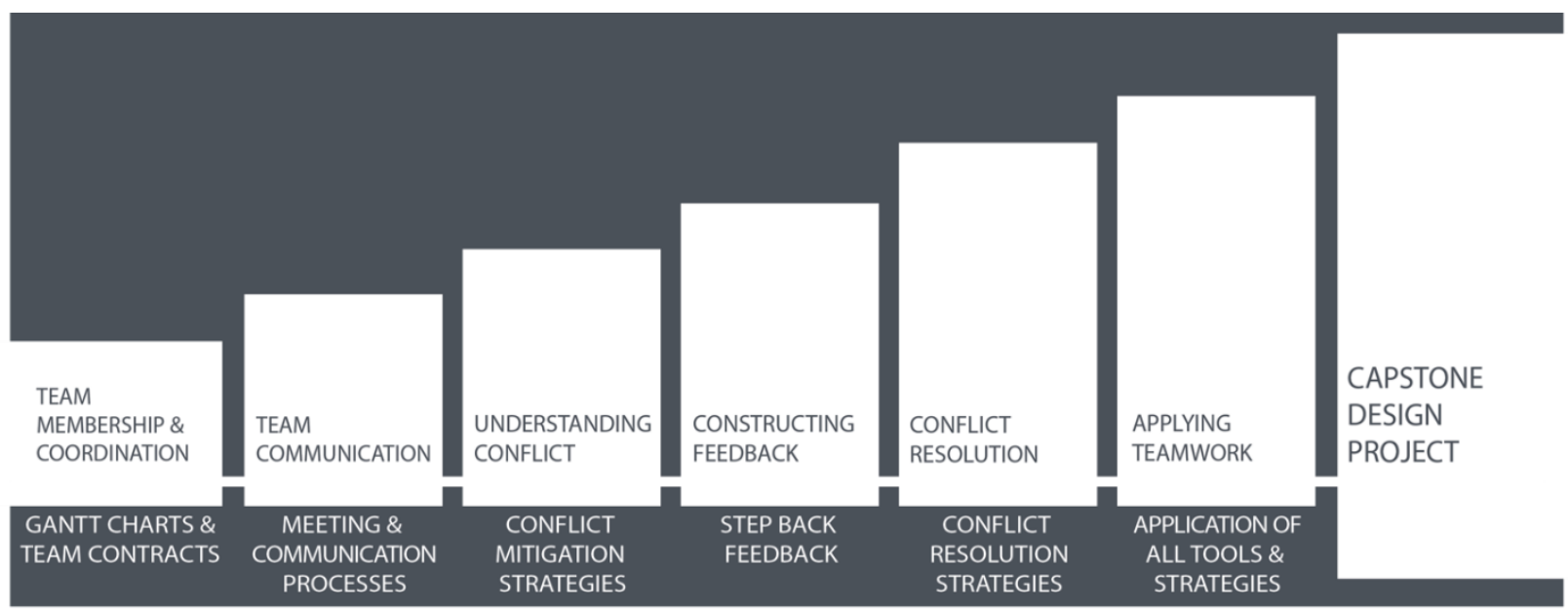

Figure 1: Teamwork teaching modules

We have previously described the first two developed modules (Hurst et al., 2016); since then, we have further refined those modules and piloted and implemented two more (Al-Hammoud et al., 2017), and are well on our way to producing all six planned modules in the series. The purpose of this paper, however, is not to outline those modules in detail; rather, we aim to reflect on the inner workings of our team, as experienced by us as team members. More generally, this is a case study on the processes of a multi-disciplinary team, presented in the context of recent and influential literature on teams and team performance.

We recognize that our team is unconventional: it was created from a group of self-selected volunteers who believed in a common mission; it includes membership from faculty, staff, and graduate students from a number of engineering departments and other university support units; and, although it is largely operating outside formal curriculum committees, it is making a concerted effort to integrate teamwork training in the various engineering programs' curricula. Borrowing from the characteristics of effective teams as described by the literature and through the use of examples, we describe our team's characteristics, processes, and challenges. Along the way, we share some of our lessons learned that may be helpful to colleagues in other universities that might seek to take a similar approach to launching new academic initiatives.

\section{Teams and teamwork}

In a comprehensive review of the literature on teamwork performance, Salas, Sims and Burke (2005) define teams as "two or more individuals with specified roles interacting adaptively, interdependently, and dynamically toward a common and valued goal” (p.559, 562). That 
interaction - "a set of interrelated thoughts, actions, and feelings" (p. 562) - is defined as 'teamwork'. Salas et al. (2005) suggest that, to be effective, teams require a number of components (the "big five"), including leadership (Hinsz, Tindale, \& Vollrath, 1997; Stewart \& Manz, 1995), mutual performance monitoring (McIntyre \& Salas, 1995), backup beha vior (McIntyre \& Salas, 1995; Porter et al., 2003), adaptability (Campion, Medsker, \& Higgs, 1993; Klein \& Pierce, 2001) and team orientation (Campion et al., 1993; Driskell \& Salas, 1992; Wagner, 1995). These five factors are facilitated by three coordinating mechanisms: shared mental models (Cannon-Bowers, Tannenbaum, Salas, \& Volpe, 1995; Zaccaro, Rittman, \& Marks, 2002; Klimoski \& Mohammed, 1994), mutual trust (Bandow, 2001), and closed-loop communication (McIntyre \& Salas, 1995), as depicted in Figure 2. In the following sections, we further describe each aforementioned characteristic and discuss their application in the context of our team.

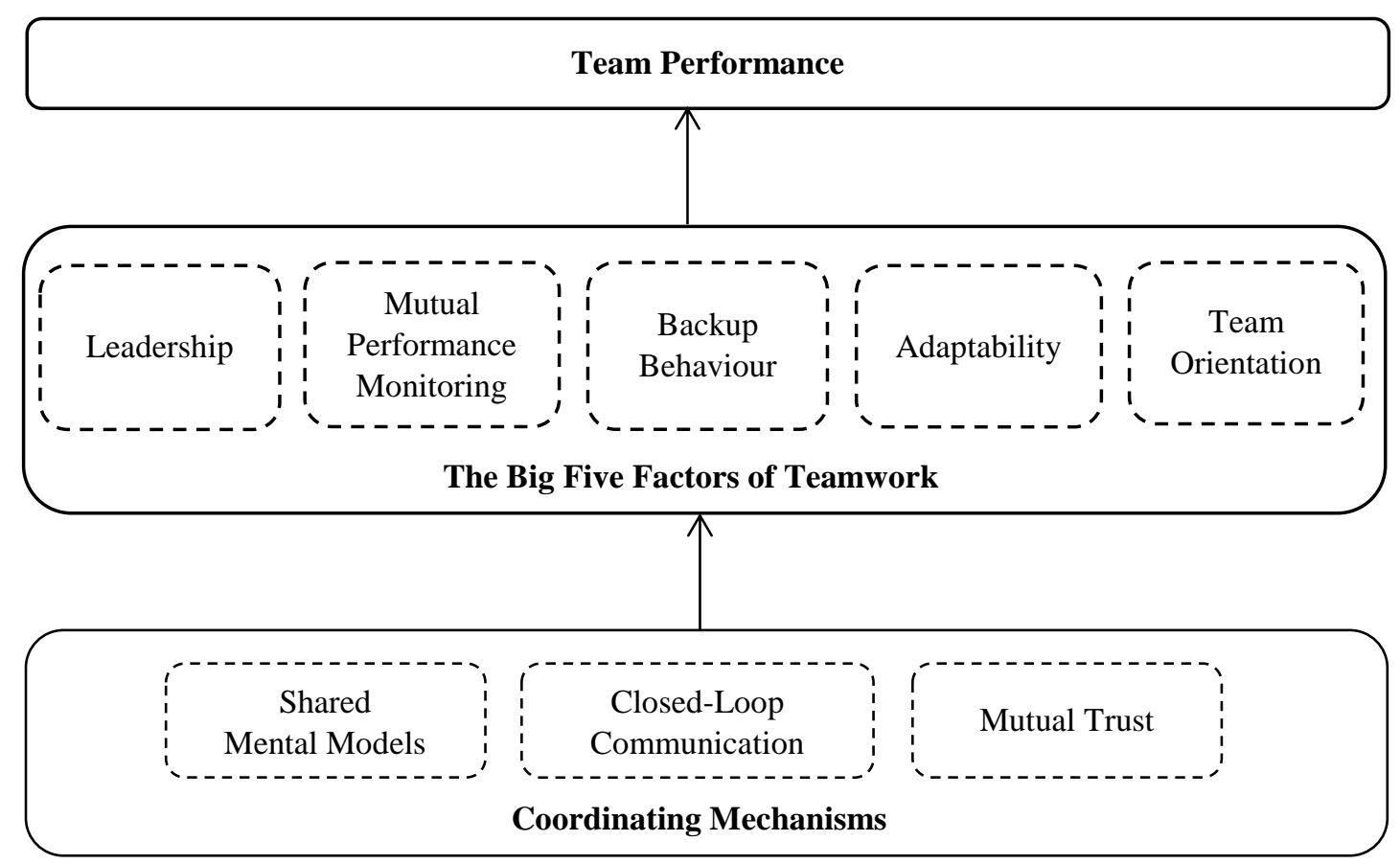

Figure 2: The "Big Five Factors" of teamwork and their coordinating mechanisms (Salas et al., 2005)

The first of the big five factors is team leadership, defined as "the ability to direct and coordinate the activities of other team members, assess team performance, assign tasks, develop team knowledge, skills, and abilities, motivate team members, plan and organize, and establish a positive atmosphere" (Salas et al., 2005, p.560). It thus includes, but is not limited to, team activities such as scheduling, resource allocation, task assignment, role clarification, and organizing meetings. Our team has its origins in 2014, when a senior engineering faculty member saw an opportunity - within the context of a wider engineering education initiative - to offer more explicit teamwork instruction to engineering undergraduate students. This faculty member first invited two individuals - a faculty member and a staff member - to join this new 
initiative, and tasked them with devising a plan of action for tackling this problem. Their first step was to conduct an environmental scan of the status of teamwork training at our university. In the process, they interviewed other internal stakeholders that had some direct experience with and knowledge of existing teamwork instruction opportunities for undergraduate students. From there, representatives from support units such as the Student Success Office (SSO) and the Centre for Teaching Excellence (CTE), as well as other faculty and staff representatives from the various engineering departments were invited to join and a new working group (team) was thus formed. Since 2014, the team size has hovered between 10 and 15 members. Different team members had different reasons for joining the team. For example, representatives from the SSO saw their involvement in improving teamwork instruction to engineering students as directly aligning with their organizational goal of supporting academic programming. Similarly, for the representative from CTE, participation in this working group fell within her mandate to support new student learning initiatives. Other team members joined the working group because they had experienced undergraduate engineering students' lack of teamwork skills in their own classrooms and acknowledged their great importance to engineering professionals' ability to work effectively in teams. Finally, for many, this initiative presented an opportunity to 'teach' and assess the 'teamwork' graduate attribute, as required by the Canadian Engineering Accreditation Board (Engineers Canada, 2016).

While the team enjoyed strong membership from the very beginning, it took some time to develop the necessary role clarity within the team. In the early stages, the only clear role was that of the team leader, which was assumed by the founding faculty member. This individual developed the team's mission (to design teamwork training for undergraduate engineering students), built the team's membership, and provided guidance and moral support to increase team members' alignment with that stated mission. The leader, however, left the day-to-day organization of the activities, the assignments of tasks, and the evaluation of the team's effectiveness to other team members. It was up to team members to, collectively, select which individuals would be best suited to contribute to the various team activities and tasks.

As the team gained some experience and understanding of the module development process and team members' task allocations, a 'role clarity' document was drawn up that more formally outlined the steps in the development of each module - from initial design to hand-off. For each module, a standardized design cycle is used, with five development phases, as depicted in Figure 3. The document also outlined the roles and responsibilities of the main organizational stakeholders at each project phase, without, however, specifying roles of individuals beyond what was prescribed by their organizational affiliation. 


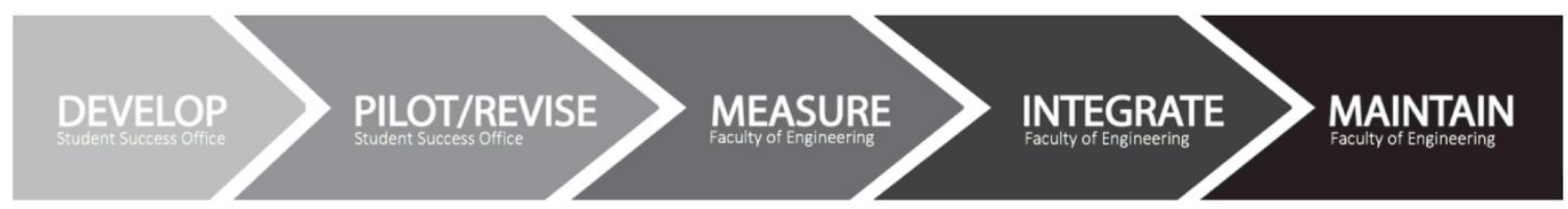

Figure 3: Module design process

We have thus taken a collaborative approach to ensure appropriate development, delivery and measurement of each module. This allows stakeholders to review and redefine the position and scope of the series of modules, as necessary. Development of each module begins by reviewing the literature on teams and reported best-practices, as well as by conducting an environmental scan of students' needs. Modules are designed such that they can be easily integrated into their host courses; the application of intended teamwork skills is kept flexible to ensure easier adoption into a variety of course settings. Next, each module is piloted in a number of engineering classrooms. Key stakeholders - faculty, staff, and students - observe the pilot deliveries, review participant feedback, and recommend content and delivery revisions, as needed. The third step in our cycle is to measure the effectiveness of the pilot. Our measurement strategy is to design pre- and post-tests that not only evaluate the content and delivery of the module but that also gather key metrics for accreditation purposes. This data is also used to showcase the effectiveness of the modules to gain faculty and student buy-in for future offerings. During the integration stage, a plan is derived for the longer term integration of the module into appropriate courses/environments. Finally, the modules are inserted into specific courses with the expectation that all future offerings of the module will be delivered by the course instructor for the course, sometimes in combination with some online instruction. This role clarity document, which has undergone several revisions since its initial draft, provides a framework that allows various team members to take on tasks and responsibilities best fitting their capacity and expertise: representatives from the SSO design the modules; faculty and staff members from the different engineering programs participate in pilot-testing, suggest revisions, and find receptive instructors and suitable courses in which to deliver the modules; and representatives from CTE support efforts to meet student learning objectives. The team holds frequent meetings to coordinate logistics and resources and to share information. This high level role clarity combined with consistent touch points has positively impacted the team's performance, especially when considering that all participants have joined this team on a volunteer basis.

The second of the "big five" factors of teamwork is mutual performance monitoring, defined as "the ability to develop common understandings of the team environment and apply appropriate task strategies to accurately monitor teammate performance" (Salas et al., 2005, p. 560). In practical terms, mutual performance monitoring means giving and receiving feedback between team members to facilitate task progress and improvement. Our team displays strong performance monitoring norms. Although individuals have adjustable autonomy (Salas et al., 2005) to perform their tasks, they frequently seek feedback from other team members. For example, representatives of the SSO who are responsible for creating each module's initial 
design normally share all plans and supporting materials with the team throughout the design process, soliciting feedback at every stage. Similarly, in pilot (as well as some subsequent) offerings of modules, a number of team members review the activities and provide feedback to facilitators and the rest of the team. Finally, the team has also made efforts to communicate its work to, and seek feedback from, external project stakeholders. In particular, team members have conducted interviews with instructors of capstone design courses, as well as a systematic survey of graduating engineering students. The purpose of these efforts has been to understand the stakeholders' perceptions and perspectives on the challenges students face in capstone design teams, in order to more effectively tailor content of the modules to student needs.

This level of role accountability and the consistent giving and receiving of feedback was not present from the beginning; team dynamics have significantly changed throughout the team's history. The team's progress has, at times, been threatened by disengagement on the part of some team members, lack of progress resulting from a large variety of opinions and unclear decision making process, temporary gaps in representation from some engineering programs, fluid membership, and the team becoming - at times - simply too large to manage effectively. Temporary disengagement and loss of accountability threatened the effective communication of key messages to target team members. In response, the team has more mindfully delineated membership needs and goals, increased documentation, and created smaller sub-teams within the larger team to tackle mission-critical tasks. For example, a small 'assessment' sub-team was created to develop, implement, and report on the measurement of effectiveness of each module as well as the series as a whole. Sub-team meetings have generally had better attendance, resulting in a more productive and efficient use of team members' time.

The third of the "big five" factors of effective teams is backup behaviour, or "the ability to anticipate other team members' needs through accurate knowledge about their responsibilities. This includes the ability to shift workload among members to achieve balance during high periods of workload or pressure" (Salas et al., 2005, p. 560). In teams with strong backup behaviour, team members have an understanding of each other's skill sets, workload, and expectations, so that they can seek or offer help when necessary to avoid frustration or wasted time. Our team displays backup behavior to a good extent. In cases when some team members have lacked expertise to complete certain tasks more effectively, other team members have stepped up and offered assistance. For instance, when it came to developing evaluation methods to assess the modules' effectiveness, the team members who had more expertise in learning assessment stepped up to assist the person in charge of developing the assessment methods. Backup behaviour is particularly crucial to a team's adaptability - the fourth of the "big five" factors, which is described as identifying cues (i.e., changing internal or external conditions) that necessitate adjustment of team strategies, such as its plan, methods, and practices (Salas et al., 2005). In our case, the need to integrate teamwork modules into existing courses has posed significant uncertainty and risk to the success of both individual modules and the series as a 
whole. So far, the team has relied on the interest and goodwill of course instructors to provide lecture or tutorial time in which to hold the modules, as well as to position the modules as a relevant part of both the course and the students' development as engineers. This has required the team to remain flexible and willing to deviate from the planned design and delivery of modules, by often making significant changes to modules both in the development phase and following their first offering. This has included having to run the first module (which was developed on the assumption that students are relatively unfamiliar with one another) very late in the academic term, splitting modules across two sessions, accommodating last-minute changes in timing, and being flexible in the delivery of the module to accommodate for shorter available time slots. For example, on one specific occasion an instructor was able to only free up one hour of lecture time for a two-hour teamwork module. To address this constraint, the team recorded some of the module's instruction on video, so that students could access a portion of the module's content outside of class. The team's adaptability is largely due to the team members' shared ownership of modules, combined with the shared goal of delivering the best-possible learning experience around teamwork. Many unexpected challenges have largely been overcome by individuals rising to the occasion and putting in significant personal effort to ensure successful module delivery.

As already noted, a shared common goal for the team is to improve undergraduate engineering education at our university. All members of the team volunteered to be part of an initiative that, while perceived as important to the development of well-rounded engineers, would nonetheless be considered by most to provide limited opportunities for career advancement and recognition. The efforts of the group aligned with the paid duties of only some of the team members. Some individual goals - for example reducing team conflicts that an instructor with a project-heavy teaching assignment will need to handle, or increasing the number of publications in the area of research in engineering education - tended to be recognized after joining the team rather than being a motivation for initially joining. In addition, none of the team members came to the table with the belief that they were required to participate because they had been instructed to do so by a superior. Thus the priority and importance of the values held by team members are in general agreement, particularly with regards to areas of greatest priority. Each member wants to see the initiative succeed and is motivated to find appropriate solutions within that same value structure. Team members are willing to compromise with regards to their lower priority goals to increase the likelihood of success of the initiative. In that sense, team members share a strong team orientation, which Salas et al. (2005) identify as the last of the big five factors. It is defined as "the propensity to take other's behavior into account during group interaction and the belief in the importance of team goals over individual members' goals" (Salas et al., 2005, p. 561). Studies have found that strong team orientation leads to increased task involvement and participatory goal setting (Driskell \& Salas, 1992). As our team's overarching goals almost exclusively provided motivation for becoming a member, team members have benefitted from strong team orientation, especially with regards to the overall team vision. 
The big five factors described above are supported and mediated by three other factors, namely communication, shared mental models, and mutual trust. Closed-loop communication is defined as "the exchange of information between a sender and a receiver irrespective of the medium" (Salas et al., 2005, p. 561), and implies not only that information is received by the receiver as intended by the sender, but also, that the sender is made aware of this. Our team has established strong communication norms. Members communicate frequently via phone and email and hold regularly scheduled meetings with clear agendas that are circulated in advance of each meeting. The lack of clear hierarchy in the team encourages more open discussion and sharing of opinions and experiences by all members. Coordination of team activities is also facilitated by mutual trust, "the shared belief that team members will perform their roles and protect the interests of their teammates" (Salas et al., 2005, p. 561). In practice, mutual trust is about trust in information sharing and in the expertise and morals of other team members, leading to productive conversations and proper task assignment. In our team, initial familiarity between team members helped establish a strong mutual trust based on which the team members could freely share their resources (e.g., a valued Qualtrics account) with each other. In addition, most team members are perceived as very reliable in terms of performing the shared tasks and deliverables. Ultimately, the catalyst for our team's effectiveness are the shared mental models - "... knowledge of the structure of the relationships among the [team] tasks... and how the team members will interact" (Salas et al., 2005, p. 561) - possessed by team members, who share a common understanding of the team's purpose, tasks, and expectations. This gives team members predicting power to anticipate others' needs and necessary changes as the work progresses. Team members have a strong conviction in the mission of integrating the teaching of teamwork skills into the engineering students' classroom experiences. Moreover, the modules' development cycle necessitates early involvement from a majority of team members, who are actively involved in brainstorming of modules' content, before specific team members take a larger ownership of the tasks in later stages.

Besides the main characteristics of an effective team defined in the literature, DeChurch and Mesmer-Magnus (2010) recognized affective components - motivation and positive affect towards the work - to have an impact on a team's performance. Our team members value the purpose of our project and are motivated to pursue its goal. When the initiative takes a step forward, there is more than just the satisfaction of seeing progress: we can directly see and measure the impact of our work on the students we are teaching. Additionally, the initiative has facilitated the meeting of the many like-minded faculty and staff which exist at our university, an especially valued outcome in a highly siloed environment such as ours. Being able to meet and speak with people who see the intrinsic value in teaching has provided benefits to all, both in, and outside, of this initiative.

3. Dealing with conflict 
Experiencing conflict is an unavoidable part of working in teams. However, it is the methods/strategies taken to address conflict that may result in either positive or negative team outcomes. Rahim (2002) proposes a two-dimensional model through which he explains various methods that can be adapted to address conflict (similar to the framework developed by DeChurch and Marks (2001) for conflict styles). The two dimensions are: concern for self, and concern for others. The degree to which a conflict is of self-concern or of the team's concern affects which of the following conflict resolution strategies may be most appropriate: 1) integrating (i.e., accepting the other side's perspective and differences and looking for alternatives to solve the problem in a way that is acceptable to both sides), 2) obliging (i.e., attempting to minimize the differences and emphasizing the commonalities to satisfy the other side's concerns), 3) avoiding (when a team member avoids satisfying his/her needs), 4) compromising (a give-and-take whereby both parties give up something to make a mutually acceptable decision), and, 5) dominating (a team member forces his/her idea to the team).

Most conflicts experienced by our team were related to choosing content to be included in each module. These conflicts were generally resolved through the conflict resolution strategies of integration and compromise. A prominent example of this type of conflict occurred during the design of the third module, which is an introductory session on conflict management. One of the topics covered in this module is the effect of different personality types on a team's effectiveness. The module was envisioned such that students would learn about different personality types, take a personality test, and then discuss how differences in personalities might cause conflict and affect the choice of conflict resolution strategies. There are a number of personality dimensions (and related tests) that are evaluated and widely used in industry. Our team members were in strong disagreement with regards to which personality test to use. A number of members advocated the use of the Big 5 Inventory (BFI) (Goldberg, 1990), as a rigorously derived and validated personality framework. There is a large literature on BFI and teamwork, and as such, it was believed that the use of BFI would lead to an enriched module. Another member, however, proposed the use of the Myers-Briggs Type Indicator (MBTI) - a personality test that, although widely recognized and used in industry and popular culture, falls short on a number of validity and reliability measures (Furnham, 1996; Pittenger, 1993). This member's argument was that if students took the BFI personality test without dedicated support to help them interpret and put the results in context, it may affect their psychological wellbeing, especially if the results were deemed as a negative assessment of their personality. In contrast, MBTI has a more 'positive' outlook on personality traits, placing no negative associations on any of the personality types. The members that proposed the use of BFI placed a stronger value on using an academically rigorous personality test, while the member that proposed the use of the MBTI placed a stronger value on the students' experience engaging with the personality test. Both sides voiced their arguments in various meetings and were generally understanding of the other side's concerns. The conflict was resolved through compromise and integration. The MBTI 
was ultimately used in the module; however, the module facilitators strongly emphasized the limitations of the MBTI and described its use for illustrative purposes only. In addition, while the MBTI was accepted as one way to illustrate personality conflicts, the session developer was successfully able to integrate other sources of conflict into the content of the module (e.g., power and value asymmetry), thus reducing the overall emphasis on the MBTI in the module.

Another source of conflict in the team has been goal ambiguity. While the team's long term and official goal - developing instructional modules to improve students' teamwork skills - was clear and accepted by the team members, the short term operative goals and how to achieve them within the context of the project were not always very clear, especially in the team's beginnings. This ambiguity caused some frustration within the team and negatively impacted team members' motivation. The resulting conflicts were generally resolved through the conflict resolution strategies of obliging and compromising. A team member was assigned to search the literature for frameworks on teamwork, on which to base the teamwork modules. Concurrently, another team member worked to break down our day-to-day goals and roles. After identifying the main teamwork skills that we intended to cover in each module, and operationalizing how we hoped to teach each skill, the team's performance significantly improved. Team members now had clear short term goals that they could work towards and a better clarity on the process to achieve them.

Even with clearly identified teamwork skills and clearer operational goals, some conflicts were still experienced when it came to developing an assessment plan for the initiative. Different team members had sometimes conflicting opinions on how the assessment of the individual modules and the series as a whole should be conducted. Some team members wished to reduce the work involved in assessing the modules (fearing 'over-surveying' of students), while others sought to have as thorough an assessment as possible. In addition, while it was not seen as a priority for some members of the team, aligning our assessment plan with the assessment of the 'teamwork' graduate attribute - as necessitated by accreditation requirements - is of primary importance to members that are also actively involved in and responsible for graduate attributes assessment in the faculty. To address this goal conflict (Tjosvold, 1998), the team has formed a sub group to specifically make decisions around assessment. We have employed an integrating conflict resolution strategy in which the team members discuss their points of views and come up with the assessment methods that could address various parties' concerns. While this source of disagreement within the team has not been completely resolved, the team has agreed to table this discussion until the modules have matured and sustained curriculum integration has been achieved. A similar source of conflict comes from the multiple roles that each team member has in the university; outside of the team, team members are part of well-defined hierarchical structures and are expected to adhere to specific departmental goals within their own units. In the context of the team, however, team members are part of a much flatter hierarchical structure, led by the founding faculty member. The team leader can thus sometimes feel helpless when trying to promote new goals/initiatives in the team, especially when those are in direct conflict with team members' own departmental goals. 
Team membership has remained fluid. As the initiative has progressed over time, some of the original members of the team have left to tend to other obligations, while others have joined to fill particular expertise gaps in the team. This process has at times left some team roles ambiguous or vacant, creating a potential for increased levels of anxiety and conflict for both new and existing members of the team. An example of this occurred when reporting on project progress to a funding unit. To maintain project funding, the team was required to provide an update on its activities and accomplishments in the prior year. While one team member took the lead on writing this report, all others were expected to provide feedback. This created increased anxiety for a team member that had only joined partway through the prior year; although the new team member had some knowledge about the team's activities, it was without the proper context to truly be of use. Fortunately, our team has largely mitigated potential conflicts that could develop from frequent team membership changes by nurturing a culture of inclusivity. The team cherishes the strengths of new members filling vacant roles and encourages them to bring their expertise and experiences into the team. Team members are able to contribute effectively in areas they excel, reducing the anxiety associated with not contributing in areas they may lack expertise and/or experience. Bringing in new team members from different roles within the university has also lessened any resistance the team would have had from organizational units outside the Faculty of Engineering.

In summary, although the team has experienced various types of conflicts, they have been mostly functional in nature, helping team members understand the underlying problems and steps through which they can improve their performance. These disagreements and conflicts have also brought important matters to the team's collective attention and facilitated their re-visitation and re-evaluation. Finally, the experienced conflicts have helped team members learn more about others' points of view and increased opportunities to come up with creative solutions and perform better overall.

\section{Looking ahead: long term module integration and maintenance}

While the success of the initial develop, pilot and revise phases of the modules' design cycle is to a large extent dependent upon the efforts of team members, the success of the latter stages, particularly 'integrate' and 'maintain', depends on external actors. In that respect, the team has faced two major challenges: faculty buy-in and student buy-in.

Traditionally, engineering curricula have focussed on technical content. The belief amongst faculty members varies somewhere between two extremes. In one extreme, which has been the pervasive school of thought in engineering programs, the belief is that soft skills such as teamwork are self-learned, acquired organically through significant experiences of working in teams on engineering problems, whether in academic or industry contexts. In the other extreme, 
the belief is that if a skill is required, it should be taught explicitly, through planned course instruction. Despite the perceived benefit of improving students' employability, the burden of adding significant and meaningful soft skills training is difficult to overcome in already overloaded engineering curricula. Thus, faculty buy-in of piloting and integrating teamwork modules into courses is a continuing challenge, yet key to the long term sustainability of the initiative and ultimate success of the team. There have been cases when instructors have agreed to integrate a module into a course, only to change their mind a short time before implementation, causing frustration for the team members involved. In this regard, the support from other team members has been crucial in helping the team brainstorm alternative solutions and maintaining a positive attitude when faced with obstacles.

Engineering students do not generally place a strong value on teamwork skills (Nguyen, 1998). The prevailing wisdom among students is that prior team experiences - on sports teams, for example - have provided ample training to perform effectively in teams. While these are no doubt of significant relevance, the high complexities of engineering projects require engineers to work collaboratively, thus necessitating meaningful and explicit teamwork training. While engineering students (especially those in first year) have experienced working in teams of peers, most of whom they know well, in professional settings engineers are expected to contribute to new teams, and thus need to quickly establish trust and communication norms with new team members. Until a student has faced an experience where they need to truly rely on their teammates, especially if these teammates are new acquaintances, they struggle to understand the importance of teamwork skills. Student resistance in some first-trial module deliveries have caused frustration to team members directly involved in the design of these modules. While disappointing, this initial feedback led to improved module designs that more explicitly highlight the importance of teamwork skills to students' academic and employment success. At the University of Waterloo all engineering students complete a series of co-op work terms, so skills that will help students thrive in both the interview process and in subsequent employment have direct and immediate relevance for students. In addition, it is hoped that collected data on graduating students' self-assessment on teamwork skills will help to justify the need for these teamwork modules to faculty and students alike.

Significant additional challenges loom on the team's horizon. First, we expect integration of the modules into the second half of the curriculum to be significantly more difficult than in the first half, as a result of the difference in course types (more specialised courses with significant numbers of electives). Second, there is a need to move the modules into an ongoing delivery mode; this will eventually imply reduced or eliminated involvement of staff from the Student Success Office, who are currently instrumental in both developing and delivering the modules. With that transition, crucial team members will eventually have to step down from the team. Ensuring the continued and regular delivery of the modules together with their ongoing maintenance and development is a significant challenge to be overcome in the coming years. 


\section{Conclusion}

The team outlined in this paper recognizes the importance of teaching teamwork to engineering undergraduates. To accomplish this, it has chosen a method which lies mid-way between the two extremes found in typical engineering curricula, namely self-learning and explicit course instruction. In the selected model, the cost to a specific course, or academic term, is small, and the distributed nature of the modules (once per term for the first three years of the program) enhances their impact by keeping teamwork always "front of mind" for students.

Upon reflection, the success of the team's initiative can be largely attributed to the team's characteristics as a well-functioning team, made up of people with complementary expertise which covers the broad spectrum required to teach teamwork skills to engineering students while navigating significant and varied resource and curriculum constraints in each engineering program. This initiative has brought together people with varied domain knowledge, encompassing not only the various engineering disciplines, but also other units in the university at large. As the work has progressed, team members have (perhaps inadvertently) internalized much of the teamwork instruction that has been included in the modules. Increased theoretical and practical knowledge of teamwork concepts has directly affected team members' own teamwork skills, leading to better team outcomes and performance. In that regard, the process of reflection necessitated by writing this paper gave us a valuable opportunity to look back at our own team processes, including our sources of strength as well as conflict. We believe this experience helps us better relate to student needs and enables us to enrich our teaching of teamwork concepts with our own real examples of team experiences, overall increasing the authenticity of the instruction.

\section{References}

Al-Hammoud, R., Hurst, A., Prier, A., Mostafapour, M., Rennick, C., Hulls, C., Jobidon, E., Li, E., Grove, J. \& Bedi, S. (2017) Teamwork for engineering students: Improving skills through experiential teaching modules. Proceedings of the 2017 CEEA Annual Conference, Toronto, Ontario

Bandow, D. (2001). Time to create sound teamwork. The Journal for Quality and Participation, $24(2), 41$.

Campion, M. A., Medsker, G. J., \& Higgs, A. C. (1993). Relations between work group characteristics and effectiveness: Implications for designing effective work groups. Personnel Psychology, 46(4), 823-847.

Cannon-Bowers, J. A., Tannenbaum, S. I., Salas, E., \& Volpe, C. E. (1995). Defining competencies and establishing team training requirements. In R.A. Guzzo, E. Salas, \& Associates (Eds.), Team Effectiveness and Decision Making in Organizations, 333- 380. San Francisco: Jossey-Bass. 
Coleman, P. T., Kugler, K., Mitchinson, A., Chung, C., \& Musallam, N. (2010). The view from above and below: The effects of power and interdependence asymmetries on conflict dynamics and outcomes in organizations. Negotiation and Conflict Management Research, 3(4), 283-311.

DeChurch, L. A., \& Mesmer-Magnus, J. R. (2010). The cognitive underpinnings of effective teamwork: a metaanalysis. Journal of Applied Psychology, 95(1), 32-53.

Driskell, J. E., \& Salas, E. (1992). Collective behavior and team performance. Human Factors, 34(3), 277-288.

Engineers Canada (2016) Accreditation Criteria and Procedures, ISSN 1708-8054, 15, available at: http://www.engineerscanada.ca/accreditation-resources

Furnham, A. (1996). The big five versus the big four: The relationship between the Myers-Briggs type indicator (MBTI) and NEO-PI five factor model of personality. Personality and Individual Differences, 21(2), 303-307.

Goldberg, L. R. (1990). An alternative" description of personality": The big-five factor structure. Journal of Personality and Social Psychology, 59(6), 1216.

Hinsz, V. B., Tindale, R. S., \& Vollrath, D. A. (1997). The emerging conceptualization of groups as information processors. Psychological Bulletin, 121(1), 43.

Hurst, A., Jobidon, E., Prier, A., Khaniyev, T., Rennick, C., Al-Hammoud, R., Hulls, C., Grove, J.A., Mohamed, S., Johnson, S.J. \& Bedi, S. (2016). Towards a multi-disciplinary teamwork training series for undergraduate engineering students: Development and assessment of two first-year workshops. Proceedings of ASEE's 123rd Annual Conference \& Exposition, New Orleans, Louisiana.

Klein, G., \& Pierce, L. (2001). Adaptive Teams. In Proceedings of the 6th International Command and Control Research and Technology Symposium.

Klimoski, R., \& Mohammed, S. (1994). Team mental model: Construct or metaphor? Journal of Management, 20(2), 403-437.

McIntyre, R. M., \& Salas, E. (1995). Measuring and managing for team performance: Emerging principles from complex environments. In R.A. Guzzo, E. Salas, \& Associates (Eds.), Team Effectiveness and Decision Making in Organizations, 149-203. San Francisco: Jossey-Bass.

Nguyen, D. Q. (1998). The essential skills and attributes of an engineer: A comparative study of academics, industry personnel and engineering students. Global Journal. of Engineering Education, 2(1), 65-75.

Nurmi, N., Bosch-Sijtsema, P., Sivunen, A., \& Fruchter, R. (2009). Who shouts louder?: Exerting power across distance and culture. Proceedings of the 2009 International Workshop on Intercultural Collaboration, 71-80.

Pittenger, D. J. (1993). Measuring the MBTI... and coming up short. Journal of Career Planning and Employment, 54(1), 48-52.

Porter, C., Hollenbeck, J. R., Ilgen, D. R., Ellis, A. P., West, B. J., \& Moon, H. (2003). Backing up behaviors in teams: The role of personality and legitimacy of need. Journal of Applied Psychology, 88(3), 391-403.

Rizzo, J. R., House, R. J., \& Lirtzman, S. I. (1970). Role conflict and ambiguity in complex organizations. Administrative Science Quarterly, 15(2), 150-163.

Salas, E., Sims, D. E., \& Burke, C. S. (2005). Is there a "big five" in teamwork? Small Group Research, 36(5), 555599.

Tjosvold, D. (1998). Cooperative and competitive goal approach to conflict: Accomplishments and challenges. Applied Psychology: An International Review, 47(3), 285-342.

Shuman, L. J., Besterfield-Sacre, M., \& McGourty, J. (2005). The ABET "professional skills"—Can they be taught? Can they be assessed? Journal of Engineering Education, 94(1), 41-55.

Stewart, G. L., \& Manz, C. C. (1995). Leadership for self-managing work teams: A typology and integrative model. Human Relations, 48(7), 747-770.

Wagner, J. A. (1995). Studies of individualism-collectivism: Effects on cooperation in groups. Academy of Management Journal, 38(1), 152-173.

Zaccaro, S. J., Rittman, A. L., \& Marks, M. A. (2002). Team leadership. The Leadership Quarterly, 12(4), 451-483. 